\title{
Research on Service System of Medical Library Technology based on Multimedia Data Mining
}

\author{
Haitao $\mathrm{Li}^{1 \text {, a }}$ \\ ${ }^{1}$ Zaozhuang University, China \\ ${ }^{\mathrm{a}}$ zzlwr@163.com
}

\begin{abstract}
Objective: This paper aims to solve the current problems faced by university library, which is raised with the rise of the development of network and digital library. Methods: This paper first introduces the development of libraries in Medical College and University in China. Then it analyzes the current problems faced by university library and puts forward the application of data mining technology to carry out personalized information recommendation service idea. At the same time, it introduces the basic theory of data mining and its research status. At last, it introduces the classification of books and knowledge in the ILAS system. Results: From the Research on service system of medical library technology based on multimedia data mining, we know that Based on the book circulation data mining, it draws the reader borrowing related degree to realize the books online recommendation. Conclusion: Mining association rules is an important data mining task, which is a key issue in the field of data mining research and application. Therefore, it is important to study the service system of medical library technology based on multimedia data mining.
\end{abstract}

Keywords- Multimedia; Data Mining; Medicine; Library; Research and Application

\section{INTRODUCTION}

With the rise of the development of network and digital library, university library also began to enter the digital age. Automatic management system existed in university library stores bibliographic data, a large number of readers borrowing and returning data, bibliographic retrieval records, Web access records. However, the information management system of university library used only a simple statistical analysis function at present, which can predict the needs of readers and books borrowing trend. The technology of data mining can find useful knowledge hidden in the huge data source. Association rules and clustering analysis technology are based on the data mining, which is studied, and its application to the university library data mining work in order to the reader's interest in reading. The utilization of books are analyzed, and a suitable Medical Library Individuation Recommendation Service systemis finally designed.

\section{THE THEORY OF DAT A MINING}

What is data mining? DM English spelling is Data Mining. As the name implies, it refers to the process of data mining, which is to find hidden information in the data, such as the trends, characteristics and correlation. One of the important processes of data mining is mining knowledge from data, also known as the process of data mining and knowledge extraction. The process of knowledge discovery in database can be in the process, which used to find the concept, classification, association, prediction, clustering, trend analysis, deviation analys is and similarity analysis and visualization of the results. Its knowledge has some discovery (Knowledge Discovery in Databases KDD).

\section{THE CONCEPTS OF DAT A WAREHOUSE}

DW that is Data Warehouse, which is a database management technology based on the establishment. The establishment of data warehouse is the distribution of data in different databases concentrated onto a shared information platform. This process must be safe, stable, effective. With the development of database system, the establishment of data warehouse based on the database management system has become the trend, in order to achieve high intelligence in knowledge management based on the database system. Data warehouse and data mining are complementary and interactive development, mining from data. Data warehouse can do the preparatory work for the data mining, so as to improve the efficiency of data mining. A data warehouse contains the preprocessed data, and these data become a unified format for the specification of data. Only on the basis of data mining will do further preprocessing

\section{A. The data mining task}

Generally speaking, there are two kinds of data mining tasks.

\section{B. The prediction}

Predictive data mining refers to knowledge property from yourself (the independent variable) content, to predict the unknown attribute (the dependent variable) content.

\section{Description}

Data mining refers to the description of the possible output in a lot of data link, such as the description of its development trend, clustering, association or Description of possible errors etc. Generally, description of data mining needs to be verified from the algorithm in the late.

\section{ANALYSIS OF METHODS OF DAT A MINING}

This paper adopts the analysis method of data mining to establish some imitate real world model by using the data, and uses these models to describe the patterns and 
relationships in the data. Data mining can establish six models: classification, regression, time series, clustering, association rules and sequential rules.

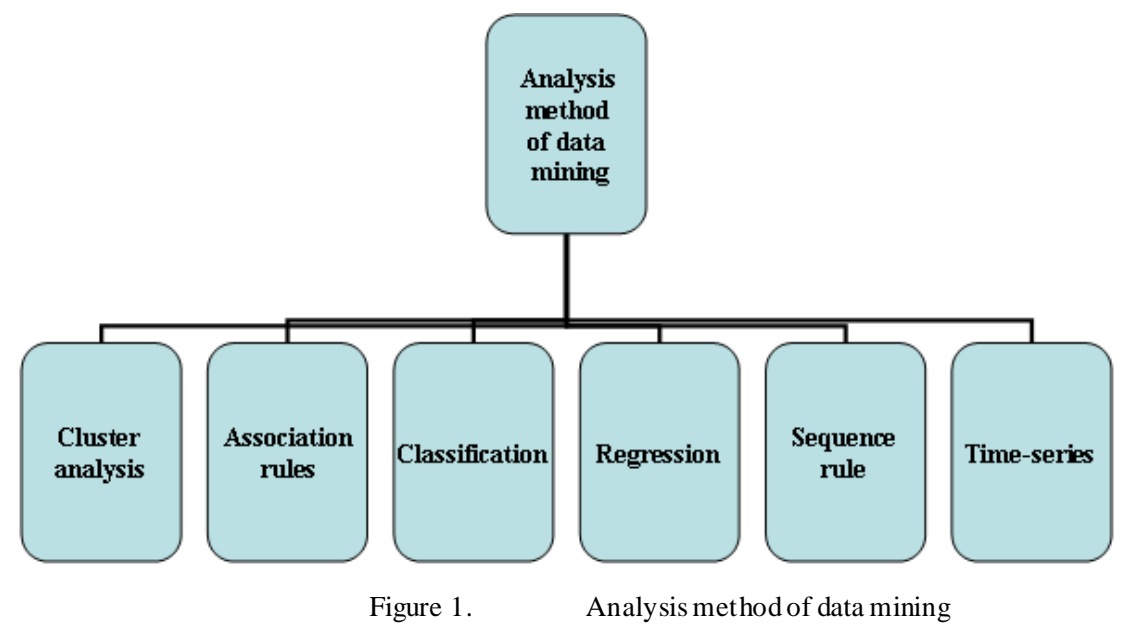

(1) Cluster analysis. Clustering is the main purpose of process data into clusters of similar or not. It not only finds differences between the clusters, and can discover the similarity of data within the cluster.

(2) Association rules. Mining association rules is to find the frequent data also appear to a given event or in the data (i.e., high-frequency project group) method.

(3) Classification. First it puts some numerical variables do arithmetic, then according to the operation result to the classification.

(4) Regression, the prediction method is widely used in numerical analysis of statistical methods, is predicting unknown continuous value in a set of existing data based on it.

(5) Sequence rule, sequence rule is a rule set up for solving connected to each group and the sequence.

(6) Time-series, time series is similar to the regression analys is. Time series obtained is different by different time measurement value.

\section{A. Introduce of library information system}

At present, foreign library automation management system application in University Libraries in China mainly include: Israel Ex-Libras Company Limited production; "American development company Dynic ALEPH" system, "HORIZON" system, and American " INNOPAC "and" UNICORN "system. They made the earliest integrated library automation system, which is composed of the Shenzhen library development" ILAS "system, then the extensively used Jiangsu huiwen-soft Ltd. production of" Huiwen document information service system "," MELINETS "system developed by Beijing University of Posts and Telecommunications, and the Beijing gold p'eng-t'u Software Technology Co. Ltd developed the" Golden Disk Library Integrated Management System "]. The follo wing will do a simple introduction of information systemapplication in library, just as shown in Fig. 2:

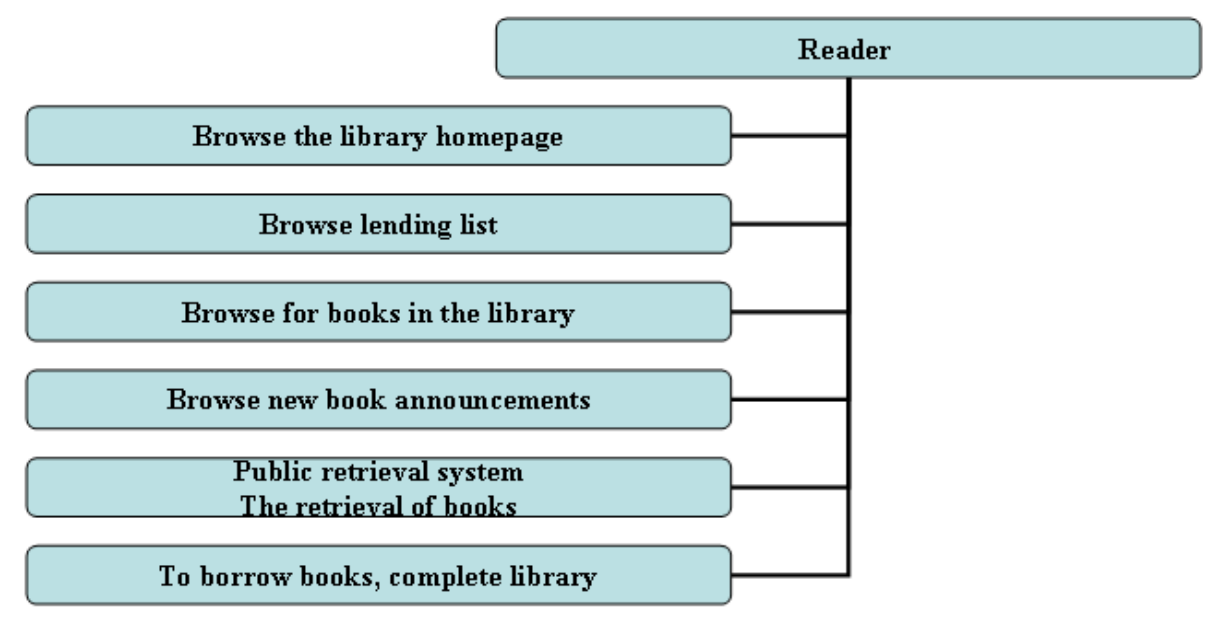

Figure 2. The flowing about borrowing 


\section{B. Introduces of the ILAS system}

ILAS (Integrated Library Automation System) is currently used in domestic university library more library information system. In 2005, ILAS III ILAS is regarded as an upgraded version with the vast number of users to meet. ILAS III supports the use of general database system currently popular, the main functions include book processing, readers borrowing and returning, online library etc..

\section{Basic modules of information system}

The realization of the library information system use function mainly includes 4 aspects at present domestic colleges and universities: the circulation management of books information management, reader information management and management. In the library information system, a large nu mber of bibliographic data storage reader circulation borrowed data, bibliographic retrieval, web data access record etc. However, with the development of colleges and universities, the time shift and these aspects of the data will continue to expand. Only a library information system existing in the basic statistics and sort the data cannot make the reasonable utilization and analysis of these data. If we apply data mining technology to library information system, we will be from the huge data source found hidden in value.

ILAS II integrated library automation system in Northwestern University library. Common businesses modules of the system include the interview management, cataloging management, collection management, continuous publication management, and circulation management and information development. There are additional modules have additional features and system admin istrator. The main structure of II library automation integrated systemis shown in Fig. 3.

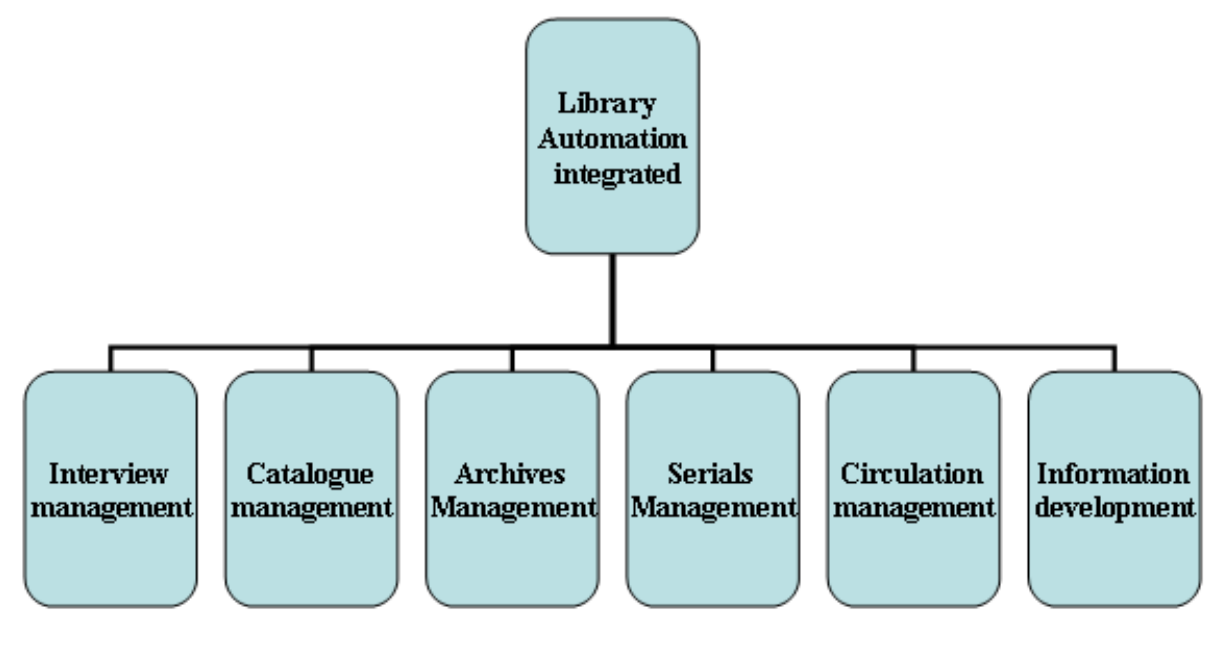

Figure 3.

Basic modules of information system

In order to remedy the deficiency of the existing library information system, recommendation system, and this paper will establish a University library personalization. The library will have better service to provide a strong scientific basis and technical support for teachers and students to purchase decision-making work of library.

\section{CONCLUSIONS}

Mining association rules is an important data mining task, which is a key issue in the field of data mining research and application. Aiming at the disadvantage of University Digital Library Service Mode and data process, it proposed the construction of personalized service system. The purpose of this research is to achieve practical problems, which cannot be personalized served to improve the existing library. Based on the book circulation data mining, it draws the reader borrowing related degree to realize the books online recommendation.

\section{REFERENCES}

[1] Chen Wenqing, Xu Tang. [Jl. microcomputer development and implementation of improved A Priori algorithm in mining association rules, 200515 (8): 155157

[2] Zhao Song, the improved [Jl algorithm, Sun Lijuan. A priori Journal of Harbin University of Science and Technology, 2007, 12 (5) 9497

[3] Guo Youqiang. Incremental mining of association rules and Realization of [Jl. computer system algorithm, 20095:5053. 